\title{
USE OF VALUE STREAM MAPPING IN A CASE STUDY IN BASEMENT CONSTRUCTION
}

\author{
Lisseth R. Espinoza ${ }^{1}$, Rodrigo F. Herrera ${ }^{2}$, and Xavier Brioso ${ }^{3}$
}

\begin{abstract}
The Value Stream Mapping (VSM) as a management tool helps evaluate the waste within the workflow. However, it must be adapted to the construction since it was originated in manufacture. This adaptation is possible through appropriate process mapping. This study aims to map the process of the basement construction system in the execution of a building in Lima-Peru city. The building in the case study will have nine basements and 11-floor levels. An adaptation of the optimization cycle for construction projects was used. It allows mapping all the relevant activities and proposing and implementing improvements in the construction system. As a result, three maps were obtained. The first one is a map of the current state (VSM 1). The second one is a map of the current state with improvements (VSM 2). Finally, a third map of the future state with improvements (VSM 3). This study demonstrated that it is possible to adapt the VSM in basement construction and the usefulness of this tool to evaluate and reduce waste within the workflow.
\end{abstract}

\section{KEYWORDS}

Value stream mapping, lean construction, production, continuous flow, VSM in construction.

\section{INTRODUCTION}

In Lima-Peru, the total time whereby value-added work is carried out on average is $28 \%$ in building projects (Guio 2001); this reveals waste in workflows. In this sense, the Value Stream Mapping (VSM), a management tool, is useful for identifying and evaluating waste within the workflow. However, despite this being a potential tool, it has not been applied frequently in the construction industry compared with manufacturing. Unlike manufacturing, a construction project is unique, with no repetition of the production process, barely tracking construction processes and data, and highly variable. VSM has potential but cannot be used directly in construction. Some adaptations are necessary to use VSM during the construction process (Fernandez-Solis and Li 2018).

1 Research, Catholic University of Santa Maria, Arequipa, Peru, rocioespinozataype @ gmail.com, orcid.org/0000-0001-5038-0863

2 Professor, School of Civil Engineering, Pontificia Universidad Católica de Valparaiso, Valparaiso, Chile, rodrigo.herrera@ @ucv.cl, orcid.org/0000-0001-5186-3154

3 Professor, GETEC Research Group, Department of Engineering, Pontifical Catholic University of Peru, Lima, Peru, xbrioso@ @ucp.edu.pe, orcid.org/0000-0002-0174-0241 
In a review study, Fernandez-Solis and $\mathrm{Li}$ (2018) identified that only nine articles are related to the implementation of VSM in the construction industry. Among these studies, the application of VSM in a tile prefabrication company showed improvements in $25 \%$ of productivity in its administration and production process (Gallardo et al. 2014). Covarrubias improved the administrative operations of a construction company (Covarrubias et al. 2016). Shou studied the value stream mapping in the shot blasting and coating industry (Shou et al. 2017). However, in construction systems, VSM was only applied to improve the structural masonry execution process (Melo et al. 2017) and the column concreting process (Germano et al. 2017). In Peru, two studies are applying with VSM, the first of them in highway projects (Román and Juárez 2014); and the second, to identify the productive flow, focusing on the identification of waste in a residential building, improving the workflow of the finishing stage (Murguia et al. 2016). Rosenbaum, S., et al (2014) applied VSM with a green-lean approach in constructing a hospital to simultaneously evaluate environmental and production wastes during the execution stage of the project. Gunduz and Fahmi Naser (2017) used VSM as a sustainable construction tool in the installation of underground pipes, and as a result, showed a cost reduction of $20.8 \%$. Therefore, this paper describes a methodology to design an integrated and customized value stream map for construction industry requirements. The approach was developed and verified based on a collaborative Project (Matt et al 2013)

Consequently, to our best knowledge, there is no previous research in the literature on projects associated with excavations and soil containment structures until now. Thus, this study aims to apply the VSM tool to improve the basement construction system in its execution stage. The case study is about constructing nine basements in a high-rise building located in Lima - Peru city during the COVID-19 pandemic. The scope of this study is focused on the excavation and construction of anchored walls. In this sense, this work seeks to answer the following research question: how to improve workflow? How to reduce non-productive activities in the basement construction system? This study carried out a VSM in current and future states to answer this question with innovative improvements.

\section{BACKGROUND}

\section{BASEMENT CONSTRUCTION}

In Lima - Peru, like many developing countries, in recent years, there is a needing to grow vertically, with buildings of 20 to 30 floors and with basements of up to 10 to 12 levels for parking vehicles (García 2020; Guio and Cayllahua 2019). However, these buildings are usually built-in reduced land areas and constructions on the sides (García 2020). This happens due to the housing deficit resulting from the migrant population from the province to the city of Lima - Peru (Santa María 2019). This context has made building companies take full advantage of land availability and make buildings taking account of height and depth to satisfy this demand (Guio and Cayllahua 2019). Based on this context, basement construction systems and deep excavations are created. It is worth mentioning that the soil in the city of Lima is highly compact and resistant, in addition to the absence of a water table, benefiting the land's stability to be excavated (García 2020; Guio and Cayllahua 2019).

Considering these conditions, the usual construction system to stabilize slopes in deep basements is the so-called anchored wall or known as a screen wall. This system consists 
of the design of reinforced concrete retaining walls of approximately $5 \times 3 \mathrm{~m}$ dimensions, which are retained through an anchor (Carbajal and Bermudez 2017; García 2020). This system is quite economical and manageable, especially in small spaces such as this case (García 2020).

\section{VALUE STREAM MAPPING (VSM)}

The Value Stream Mapping (VSM) is a Lean Production tool that allows visualizing and understanding the flow of material and information within a value chain. It is also defined as an improvement process that aims to maximize value by identifying and eliminating waste in the value chain (Rother and Shook 1998). With the implementation of the VSM in construction, it can systematically illustrate a construction stage or system with the ability to identify potential problems and waste.

The VSM considers productive activities, the times for each activity, the customers, the suppliers of the process, following a flow of value that identifies waste and shows the reasons for its existence (Pasqualini and Zawislak 2005). After identifying waste, VSM allows proposing an ideal production chain. It consists of producing only the necessary in the appropriate moment, improving the time for activities that add value to the system (Da Silva 2018).

Fernandez-Solis and Li (2018) identified VSM application in construction is hindered by the following factors: (1) with difficulty arises the repetition of the production process. Every construction project is unique. (2) most construction companies do not fully track construction processes and collect data from portraying the current state of the process and figuring out the future state. (3) concepts/elements used in VSM are defined in the manufacturing context; this differs from the construction context.

\section{METHODS}

This research is classified as an experimental-type case study based on procedures and techniques (Gil 2002). The focus of this study was the construction of nine basements entailed building screen walls. The screen wall execution process was chosen to be studied because it involves one of the most relevant activities in the budget and schedule in building projects. Therefore, the proposed improvements will significantly impact the building project (Guio and Cayllahua 2019). This study used the adaptation of the PDCA? Optimization cycle for construction projects proposed by Cabrera and Li (2014), shown in Figure 1.

This proposal is based on identifying the Value Stream Mapping and including improvements and innovations components. This procedure is subdivided (or broken down) into the following stages. (1) Definition: grouping the processes according to their sequence to shape a constructive system. (2) Measurement: diagnose the production flow to discover problems and waste (time, rework, among others). This stage defines deliverables and responsibilities; the result of this stage is the actual Value Stream Mapping (SVM 1). (3) Evaluation: in this stage, a meeting is carried out with a team shaped by the planning and engineering project members to share different approaches for a particular problem, drawing conclusions and possible solutions. The result of this stage is a future VSM (VSM2 and VSM3) (4) Intervention: once the problems are known, corrective actions are implemented. Many problems and wastes can be solved immediately by reducing non-productive time according to improved resource flow onsite. (5) Control: Finally, once most of the waste found has been reduced, other inefficiency sources and limitations of the current working method will require improved 
process innovation. For this case, an optimized VSM3 diagram is built to be implemented for future similar projects. In such a way, it would allow the building project to obtain a higher performance at levels that make the company more competitive.

\section{CASE STUDY DESCRIPTION}

This case study is justified because the company responsible for the project applies Lean principles and tools in some of the project stages, which is why this is a company that has a work team that adopts continuous improvement in its processes.

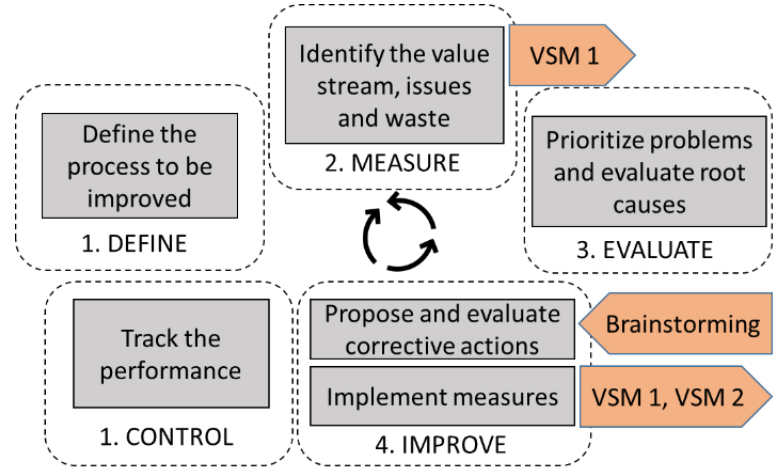

Figure 1. The adaptation of the optimization cycle proposal for construction projects by Cabrera and Li (2014)

The case study is a building destined for offices; it involves constructing nine basements destined for parking spaces and warehouses, and eleven mezzanine levels for offices. The project is located in Lima - Peru. This project is characterized by having a deep excavation of up to $30.55 \mathrm{~m}$, with a medium-sized area of $1,487.65 \mathrm{~m}^{2}$, as shown in Figure 2. The proposal was planned to make around 350 anchored walls; from them, the first eight basements were tensioned, and the latter, according to geotechnical studies, will not have an anchor. The project had nine months duration.

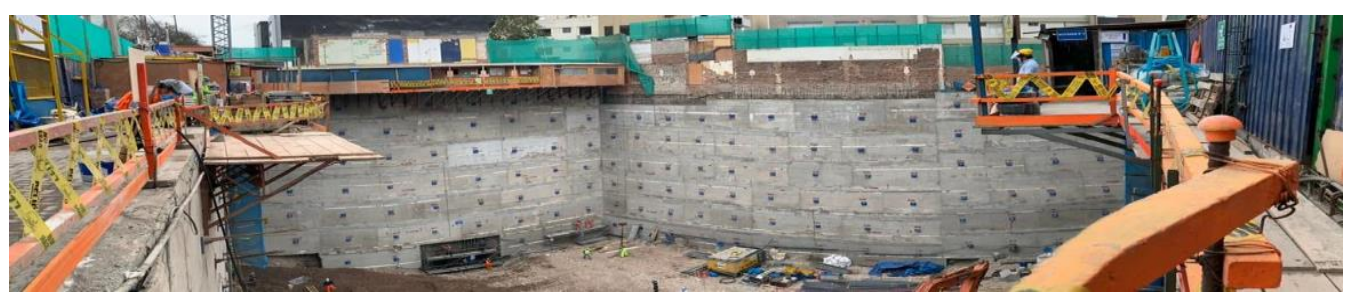

Figure 2. Panoramic view of the building of the anchored wall

The building project was paralyzed on March 15, 2020 then that the national state of emergency was declared due to the serious circumstances that affected and continue affecting life as a result of the COVID-19 outbreak (PCM 2020). Under these circumstances, as a part restart of the building project. Actions indicated in the Ministry of Health ministerial resolution in Peru (MINSA 2020) were adaptation. This adaptation involves fulfilled the $1.5 \mathrm{~m}$ distance social between the workers, Demand the mandatory use of masks, and have a limited capacity.

\section{RESULTS AND DISCUSSIONS}

\section{Current State Map (VSM1)}

As shown in Figure 3, it is a traditional construction system that uses concrete blocks 
measuring $1 \times 1 \mathrm{~m}$ on each side to support the struts, the same that support the formwork. The construction system begins with the (a) formation of a drilling safety bench, leaving the safety berm to construct screen walls. Then comes the (b) Perforation and injection, laying the cables, and the injection of the grout, following with (c) the dirty cleaning concrete of the higher screen wall and with (d) the joint splice. The (e) excavation with machinery, (f) manual excavation or manual profiling and placing of concrete grout, which provides security against any detachment. Then comes the (g) Armed and install steel mesh with the help of $\left(\mathrm{g}^{\prime}\right)$ the scaffolding placement. Sequentially comes the $(\mathrm{h})$ placement of Styrofoam for the rest of the slab. Continuing with (i) the formwork surface placement, this activity comprises the shaping of the earth base to settle the formwork panels, and ( $\mathrm{j}$ ) formwork, this is a process that is intended to be modified in this study, which comprises $(\mathrm{k})$ the of struts placement, (l) the flattening of the surface, $(\mathrm{m})$ the laying concrete blocks in the surface, subsequently (n) the buried of the concrete blocks and (o) the support and adjustment of the struts. Finally, in this sub-process, there is the (p) adaptation of an emptying platform and (q) then the placement "cachimba". The latter is about adapting a funnel shape to facilitate concrete entry made with phenolic formwork panels. Continuing with $(\mathrm{r})$ the pouring concrete, $(\mathrm{s})$ the stripping, and with $(\mathrm{t})$ the retouch for an architectural finish. Finally, (u) the placement of the anchors' caps and (v) the tauten.

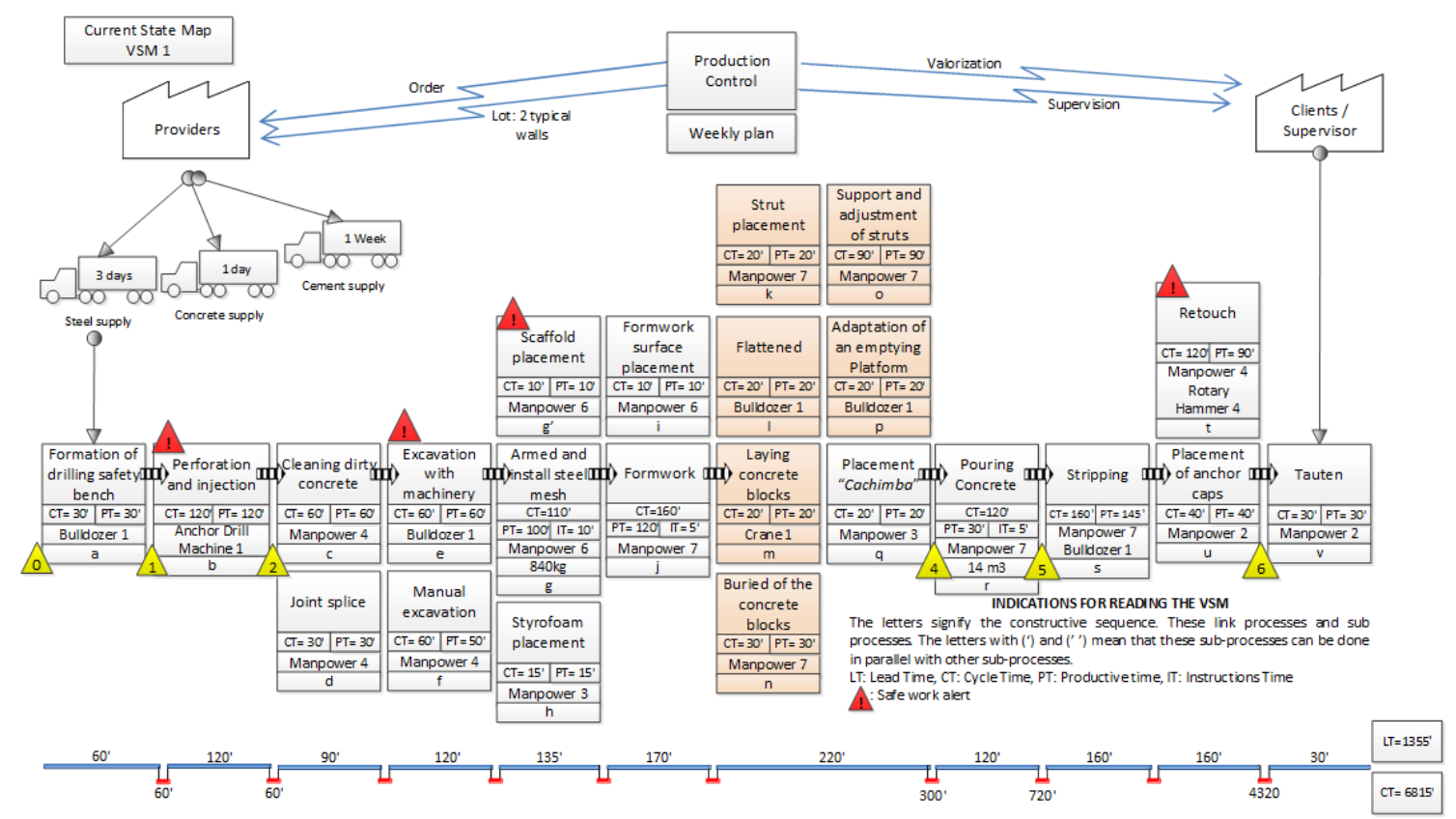

Figure 3. Current State Map (VSM 1)

This system has been running for years in the construction of screen walls (anchored). In this study using the VSM diagram, a Cycle time (CT) of 6815' and Lead Time (LT) of 1350' was observed. Some findings, such as waiting times, were identified in Figure 3, denoted with yellow triangles.

To eliminate these waiting times. First, the reason for these waits was identified. After that, brainstorming was carried out with the project team to find possible solutions for the wait-time problems. The result was a set of ideas and solutions for the wait-time issues. All the ideas were valued, and many of them were approved to be implemented (Figure 4). 
Other findings identified activities that do not add value and lead to arduous, laborious work; these are contributory activities but not productive; these are part of the formwork work and are shown in Figure 3 (orange squares). Others would modify or change these activities to minimize the construction system's time and are shown in VSM 2 (Figure 5).

\begin{tabular}{|c|c|}
\hline & Solution to eliminate waiting times \\
\hline $\begin{array}{l}\text { Waiting time for removing } \\
\text { material from the } \\
\text { excavations }\end{array}$ & $\begin{array}{l}\begin{array}{l}\text { Use another elimination system, which may be the conveyor belt } \\
\text { (as long as it is identified in which phase of elimination the project is } \\
\text { located) }\end{array}\end{array}$ \\
\hline $\begin{array}{l}\text { Waiting time for the } \\
\text { drilling machine }\end{array}$ & $\begin{array}{l}\text { Hire another drilling machine, taking into consideration the space } \\
\text { that the project has }\end{array}$ \\
\hline Wait for space & $\begin{array}{l}\text { Use of two simultaneous material removal systems. As well as } \\
\text { requesting a greater number of trucks. For both cases, it is } \\
\text { necessary to improve the scope with the earthmoving subcontract. }\end{array}$ \\
\hline $\begin{array}{l}\text { Wait time for the } \\
\text { formwork panels }\end{array}$ & $\begin{array}{l}\text { Hire more metal panels for formwork, currently there are only } 5 \\
\text { panels to formwork. }\end{array}$ \\
\hline $\begin{array}{l}\text { Wait time for the ready- } \\
\text { pix concrete to arrive for } \\
4 \quad \text { casting }\end{array}$ & $\begin{array}{l}\text { Have a scheduled end of formwork time and order concrete at that } \\
\text { time. It is mainly essential to follow up on the concrete order. }\end{array}$ \\
\hline $\begin{array}{l}\text { Wait time for the concrete } \\
\text { to set }\end{array}$ & $\begin{array}{l}\text { Use an additive to achieve concrete strength in less time, and thus } \\
\text { also remove formwork in less time. }\end{array}$ \\
\hline Wait time for tensioning & $\begin{array}{l}\text { This waiting time can be approximately } 3 \text { days }(72 \mathrm{~h}) \text { and depends } \\
\text { on the resistance curve of the concrete. }\end{array}$ \\
\hline
\end{tabular}

Figure 4. Solution proposals to eliminate waiting times

\section{Current State Map With Improvements (VSM 2)}

This is the current construction system implementing the proposed improvement mentioned in VSM 1 (Figure 3). A construction system that has already been used in different projects today. This system applies the formwork burial method. An improvement in the reduction of wait time was observed: CT of 6280 'and an LT of 1120' as shown in a VSM 2 (Figure 5).

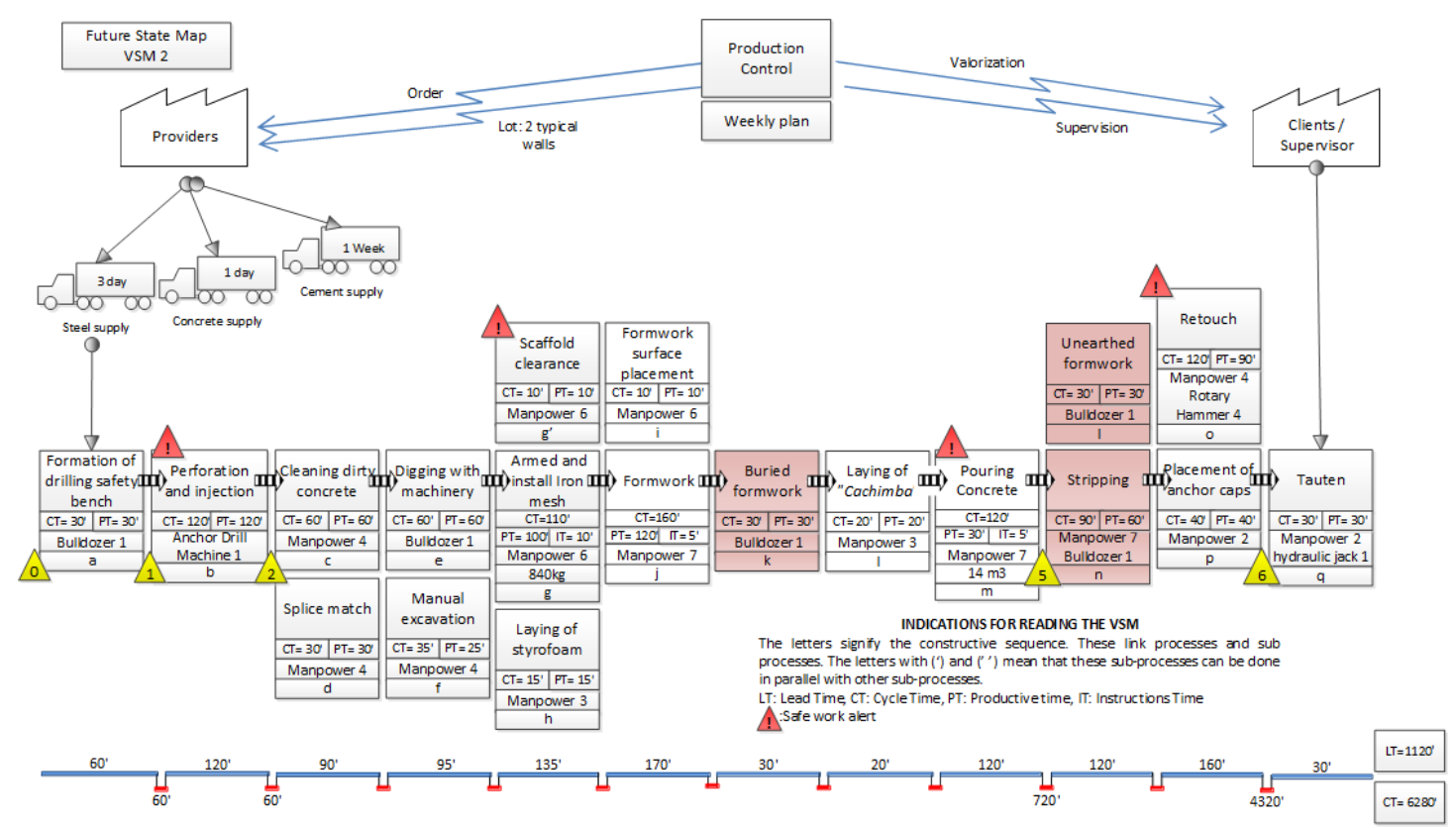

Figure 5. Current State Map with improvements (VSM 2). 
This method consists of burying the formwork with the excavation material (Figure 6.A). Some of the benefits of this method are: less time in the formwork process compared to the previous system, less formwork equipment and resources, more space on-site to use the excavation material as support for the formwork, finally, the possibility to formwork two continuous walls. However, to achieve a uniform finish, controlling the alignment and verticality is essential to place concrete blocks before the formwork. Figure 6.B shows PVC pipes filled with concrete cut in a similar dimension of the screen wall thickness; these will be used like concrete blocks. This formwork system is recommended a pre-assembled metallic formwork in order to transport it quickly with the excavator.

The VSM 2 also revealed safe work alerts (Figure 5, red triangles). Such as, that after the buried formwork, in the process of pouring concrete, the workers there was difficulty in transferring through the provisional ramp, before which the workers stated that they perceived insecurity, despite the approval of the supervision. other alerts reveal the need for inspection of machinery and scaffolding.

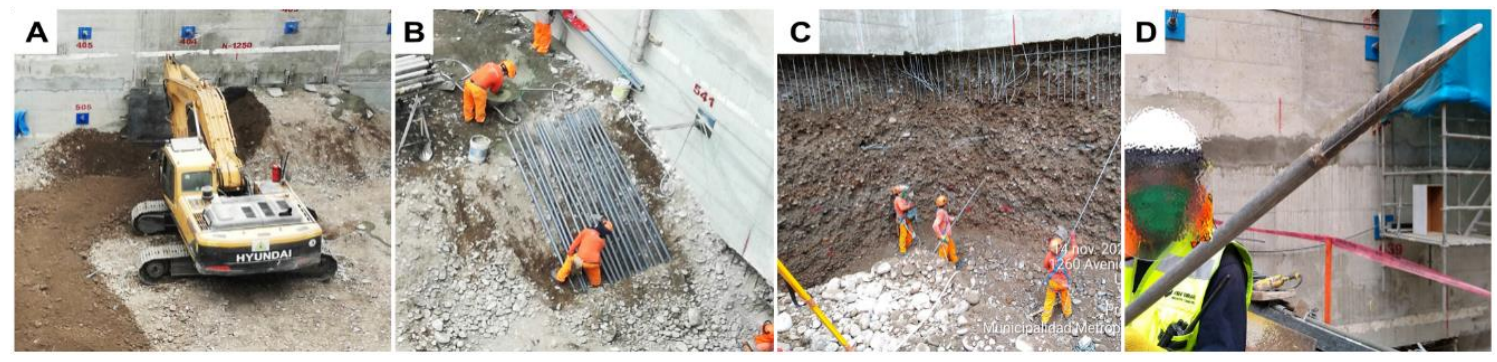

Figure 6. Improvements and innovations in basement construction.

The VSM 2 map also shows the manual excavation activity's current time show in Figure 5 (f); in this activity previously was used a heavy metallic bar as a work tool. However, this tool was enhanced toward a concrete bar with a metal tip (Figure 6.D). Compared to the metal bar, this tool became lighter due to the concrete bar's lower weight. This improvement was a contribution of a master builder. The effort worked with this tool resulted in workers' more performance and less fatigue in this activity (Figure 6.C).

\section{FUTURE STATE MAP WITH IMPROVEMENTS (VSM 3)}

This is a proposal for the construction of screen walls for the future using shotcrete concrete. An innovation proposal would eliminate formwork activities shown in Figure 5 (red squares): formwork surface placement, formwork, stripping, and retouch. This system is shown in Figure 7 and could significantly reduce the CT in 5200 'and LT in 760 '. This proposal allows a wall finish type plastering; the advantages of this system are: it does not require formwork, it does not require labour for formwork, it does not require burying the wall, it does not require demolishing hookahs, it allows having a larger area of land available for other activities.

This system has not yet been implemented; however, some pilot tests were carried out on its applicability. The new activities to make this work shown in Figure 7 (blue squares) would be: arming of the lateral formwork, laying of tecnopor, shotcrete, and scaffold clearance shown in Figure 8.

Regarding the formwork burial system (VSM 2), this system is not efficient, since it is excavated to re-bury, carrying out a rework. Thus, the new Shotcrete system shown in the VSM3 could replace it because it eliminates non-productive activities. If this new system is implemented, it is necessary to control the waste of concrete to avoid costs. 
One limitation of the study is that it was not possible to observe more evidence of the proposed innovation in the future map (VSM 3). Therefore, it was not possible to observe all the strengths and threats of this proposal either.

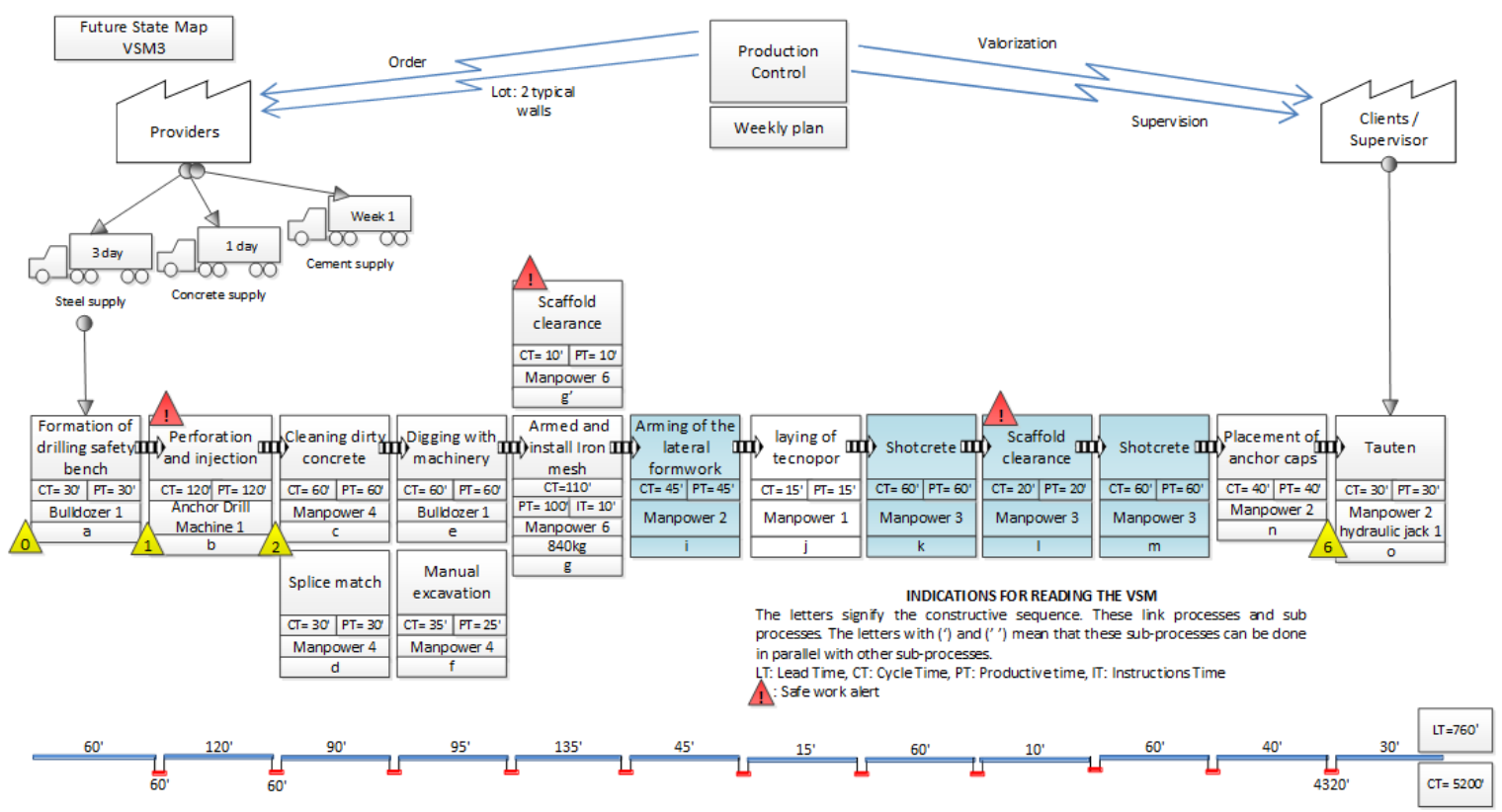

Figure 7. Future State Map with improvements (VSM 3).

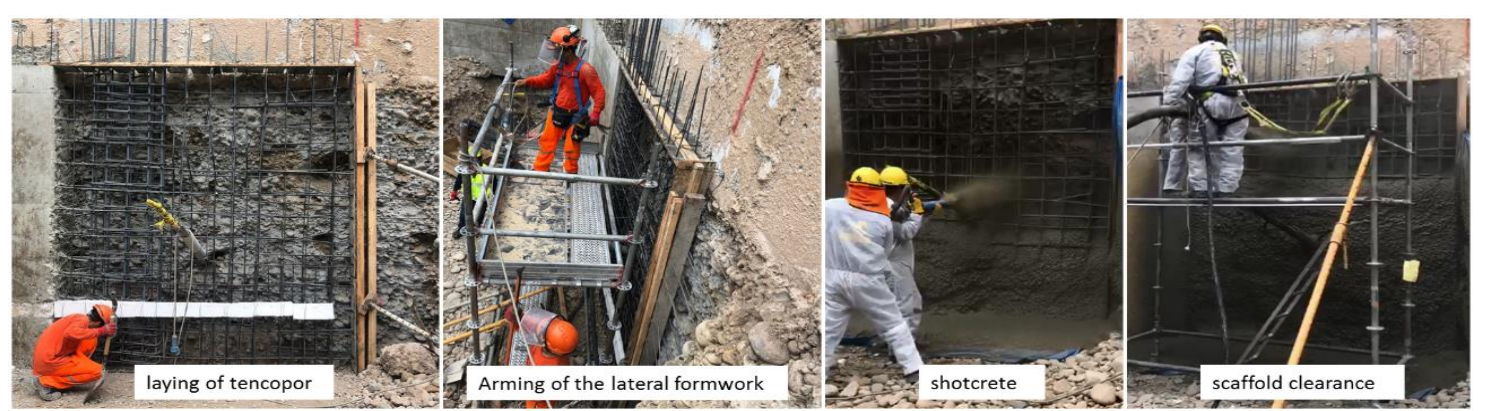

Figure 8. Additional activities with the Shotcrete System

After analyzing the VSM $1(\mathrm{LT}=1355 \mathrm{CT}=6815), \mathrm{VSM} 2(\mathrm{LT}=1120 \mathrm{CT}=6280)$ and VSM $3(\mathrm{LT}=760 \mathrm{CT}=5200)$ scenarios. It was observed that the LT of VSM2 concerning VSM1 was reduced by $17 \%$. Comparing the VSM 1 and VSM 2 scenarios, they both have a similar amount of labor. The VSM 2 Scenario, although it is the one in use today, is not preferable for security purposes.

The LT of the VSM3 in relation to the VSM2 was reduced by $32 \%$, as well as the number of workers, making this scenario the preferable one, not only to reduce the execution time but also to comply with the Measures provided for COVID-19, such as social distancing and recommended capacity (MINSA 2020). VSM, although in principle it is about identifying activities that add value in the value chain, it also allows the analysis of health and safety in the entire construction system studied.

\section{CONCLUSIONS}

The main contribution of this study is the application of the VSM tool in projects associated with excavations, where VSM improves the construction system through 3 
continuous improvement scenarios. This research answers the research questions. A workflow can be enhanced by identifying all the activities that add and do not add value to the construction system through the VSM. Activities that do not add value are eliminated or reduced by adopting continuous improvement strategies. Strategies that were discovered by the project team in a brainstorm, where each idea was valued. The current map VSM 2 with the improvements allowed us to implement some of the proposed solutions. The future map VSM 3 allows exposing an improvement with innovation that could be applied in future projects with the execution of screen walls, reducing the number of activities within the construction system, reducing interruptions, reducing variability times, and therefore product delivery. One limitation of the study is that this construction system is only applicable for constructing basements with screen walls or anchored walls; therefore, biased information could be produced, since there is no information in the literature to compare it. A future study could be about applying this future map VSM3 and analyzing the activities that originated with this proposal, record the waste and the duration of Cycle time (CT) and Lead Time (LT). In comparison to the obstacles identified by Fernandez-Solis and Li (2018) and in other studies. This study evidenced (1) the construction of basements has become a systematic process, emerging a repetitive process, even when each project is unique (2) Data collection was not a problem since the company controls the activities. (3) There was no difficulty in adapting the concepts/elements used in the VSM; however, it would be helpful to add other concepts/elements typical of the construction.

\section{ACKNOWLEDGMENTS}

The author would like to thank the company that provided data for this study.

\section{REFERENCES}

Cabrera, B. R., and Li, G. J. (2014). "A lean-TRIZ approach for improving the performance of construction projects." 22nd annual conference of the international group for lean construction: understanding and improving project-based production, Oslo, Norway, 883-894.

Carbajal G. G., and Bermudez P. D. L. (2017). "First run study and process optimization in the construction of anchored walls." Research projects. Faculty of Sciences and Engineering, Pontifical Catholic University of Perú, Lima, Perú.

Covarrubias, A., Mourgues, C. and Arroyo, P. (2016). "VSM for Improving the Certificate of Occupancy Process in Real Estate Projects - a Chilean Case Study." 24th Annual Conference of the International Group for Lean Construction. Boston, Massachusetts, USA, Jul 2016, 20-22.

Da Silva Etges, B. M. B. (2018). "Value-Adding Activities Level in Brazilian Infrastructure Construction Companies-9 Cases Study." IGLC 2018-Proceedings of the 26th Annual Conference of the International Group for Lean Construction: Evolving Lean Construction towards Mature Production Management across Cultures and Frontiers, Vol. 2, 1323-1333.

Fernandez-Solis, J. L., \& Li, Y. (2018). "A Structured Literature Review: Value Stream Mapping (VSM) In Construction Industry." OAKTrust, Construction Science, Faculty Publications. Texas A\&M University. 1-24.

Gallardo, C. A. S., Granja, A. D., and Picchi, F. A. (2014). "Productivity Gains in a Line Flow Precast Concrete Process after a Basic Stability Effort." Journal of Construction Engineering and Management, 140(4), C4013004. 
García Martín S. (2020). "Experiencias y peculiaridades de las obras de edificación en Lima, Perú." CIMBRA Journal of the College of Public Works Technical Engineers, 418, 48-49. (in Spanish).

Germano, A. V., Fonsêca, N. J. M., Melo, R. S. S. and Moura, A. (2017). "Value Stream Mapping: Case Study in Columns Concreting." 25th Annual Conference of the International Group for Lean Construction. Heraklion, Greece, 9-12 Jul 2017, 821-828.

Ghio, V. (2001). "Productividad en proyectos de construcción: diagnóstico, crítica y propuesta.”. Pontifical Catholic University of Peru, Lima, Peru. (in Spanish).

Gil, C. (2002). "How to develop research projects." São Paulo: Atlas, 2002, Vol. 4.

Guio S, J. D., and Cayllahua H, D. (2019). "Análisis de los métodos de eliminación de material para construcción de sótanos en Proyectos que presentan suelo granular en Lima Metropolitana." Research projects, Faculty of engineering, Civil Engineering academic program, Peruvian University of Applied Sciences, Lima, Peru. (in Spanish).

Gunduz, M., and Fahmi Naser, A. (2017). "Cost based value stream mapping as a sustainable construction tool for underground pipeline construction projects." Sustainability, 9(12), 2184.

Melo, L. A. P., Lima, V. F. C. and Melo, R. S. S. (2017). "Value Stream Mapping: A Case Study in Structural Masonry." 25th Annual Conference of the International Group for Lean Construction. Heraklion, Greece, 9-12 Jul 2017, 755-762.

Ministerio de Salud (MINSA). (2020). Resolución Ministerial N ${ }^{\circ} 448-2020-M I N S A$. Lineamientos para la vigilancia, prevención y control de la salud por exposición al SARS-CoV-2. Diario Oficial El Peruano, Lima, Peru. (in Spanish).

Murguia, D., Brioso, X., and Pimentel, A. (2016). "Applying Lean Techniques to Improve Performance in the Finishing Phase of a Residential Building." 24th Annual Conference of the International Group for Lean Construction, Boston, MA, USA, sect.2, 43-52.

Pasqualini, F., and Zawislak, P. A. (2005, July). "Value stream mapping in construction: A case study in a Brazilian construction company." Proceedings of the 13th Annual Conference of the IGLC. Sydney, Australia.

Presidencia del Consejo de Ministros (PCM). (2020). Decreto Supremo No 044-2020PCM. Decreto Supremo que declara Estado de Emergencia Nacional por las graves circunstancias que afectan la vida de la Nación a consecuencia del brote del COVID19. Diario Oficial El Peruano, Lima, Peru. (in Spanish).

Rosenbaum, S., Toledo, M., and González, V. (2014). "Improving environmental and production performance in construction projects using value-stream mapping: Case study." Journal of Construction Engineering and Management, 140(2), 04013045.

Rother, M., and Shook, J. (1998). "Learning to See: Value Stream Mapping to Create Value and Eliminate Muda." v. 1.1. Oct., The Lean Enterprise Inst., Brookline, Mass.

Shou, W., Wang, J., Wang, X., and Chong, H. Y. (2016). "Examining the critical success factors in the adoption of value stream mapping." 24th Annual Conference of the International Group for Lean Construction. Boston, Massachusetts, USA, 20-22 Jul 2016.

Shou, W., Wang, J., Wu, P., Wang, X., and Song, Y. (2017). "Application of lean production with value stream mapping to the blasting and coating industry." 25th Annual Conference of the International Group for Lean Construction. Heraklion, Greece, 9-12 Jul 2017, 217-224. 